and those of the Civil Affairs Branch, U.N.R.R.A. has already received substantial allocations of other principal items including clothes, seeds and medical stores. In addition, U.N.R.R.A. has established a claim on crops still to be harvested, on clothes to be made, etc. The agricultural and industrial requirements are closely linked: if, for example, the flour mills could be started, it would be possible to send wheat into the countries assisted; and this would provide not only bread for the people but also milling offals that would produce milk and also animal manure to enrich the soil. Fishing also is to be restarted.

The third stage is reached when the agricultural and industrial life of the country is beginning to function normally; at that stage U.N.R.R.A. ceases to operate as its purposes do not include reconstruction. Organizations have been designed for dealing with the new problems that will arise. A permanent world food and agricultural organization is to be established, and a draft constitution has already been agreed. Its functions will include the collection, analysis and dissemination of information about nutrition, food and agriculture. It will promote and recommend national and international action on research and education in these subjects; also on the conservation of resources, improved methods of production, marketing and distribution, and the provision of adequate agricultural credit; it will also furnish technical assistance to Governments when required. No term is set to the operations of this body.

\section{A Medical Service in Ethiopia}

An opportunity for immediate medical serviceand especially, it would seem, for service by trained nurses-is indicated by an article by Dr. Ruth Young, formerly principal of the Lady Hardinge Medical College for Women, New Delhi, on "Medicine and Nursing in Ethiopia" (The Lancet, 797 ; June 17, 1944). Although it is difficult to assess accurately the incidence of particular diseases in Ethiopia, because no vital statistics exist, Dr. Young has been able to gather valuable information about the physique, diet and general health of the people. The physique of the people living on the plateau is fairly good, and they are strong and hardy. The common diseases are typhus, relapsing fever, pneumonia, venereal diseases, dysenteries, trachoma and such parasitic diseases as scabies, tropical ulcer, infestations with intestinal worms and malaria. Leprosy is fairly widespread; but tuberculosis is apparently not so serious a problem as it is in other parts of Africa, nor do diseases due to deficiencies in diet seem to be common. From what Dr. Young says there would seem to be as much need of agricultural and veterinary assistance as of medical help. The cows are poor milkers and, although goats are numerous, they are kept chiefly for meat and skins and are not much milked. On the other hand, any increase in production of animal food products would, it seems, be largely neutralized by the numerous fasts imposed by the Coptic Church, which, apart from a longer Lent than ours and other fasts, forbids the use of foods of animal origin on two days of every week. Butter, milk and eggs are included in these forbidden foods.

Maternal mortality is apparently low, and complieations at childbirth are not common. Dr. Young attributes this to the fact that most births are normal and to the very strong prejudice against any kind of interference at childbirth. There is no class of professional midwives similar to that which does "such untold damage in a country like India". Infant mortality is, on the other hand, probably very high. From questions addressed to women, Dr. Young learned that 176 out of 353 children born alive had died, and she concluded from the evidence available that something like 109 of these had died before the age of one year. There is also a high rate of sterility, probably due mainly to syphilis which, like gonorrhøa, is common. The chief needs at the moment are, Dr. Young thinks, intensive preventive work and the teaching of mothereraft and hygiene rather than the provision of hospital beds. There are at present no properly trained nurses. In an annotation on this interesting article, The Lancet (795; June 17, 1944) refers to the hospital to be built in Addis Ababa in memory of the late Princess Tsahai. Most of us will remember the tragic death of this young daughiter of the Emperor at the age of twenty-two. In Great Britain, while she was in exile, she qualified as a State registered nurse after training at the Great Ormond Street Hospital for Sick Children, London, and later she took further training at Guy's Hospital. R sturning home, she married the governor of a province in Ethiopia and began to organize the health service which she wished to see in her own country.

\section{Simple Teaching Apparatus in Physics}

IN his presidential address given to the Essex Science 'Teachers' Association, Lord Rayleigh asks, and discusses, the question "Are Expensive Appliances Necessary ?". In the physical laboratory a great deal can be learnt about Wheatstone's bridge by means of a wire stretched along a rough board, graduated with ink or pencil marks, with a piece of metal held in the hand to make contact with it at any point. From a purely teaching point of view this is as good, if not better than, a post-office box costing as many pounds as the other does pence. It is much less likely to muddle the beginner and will in all probability give him more insight into the physics of what he is doing. If the student has rigged it up for himself he will further get a sense of independence and achievement which he never gets by handling the elaborate constructions of the instrument maker. It is not uncommon to find people who regard an optical instrument not as an arrangement of reflecting and refracting surfaces, but as a construction of lacquered brass. The schoolboy first regards a telescope as a thing which 'pulls out'. All the essentials of the instrument can be better appreciated by sticking lenses with 'Plasticene' on a strip of wood. Helmholtz told Lord Rayleigh that as a boy he made his own telescope out of spectacle lenses and a cardboard tube. In instruments made by the instrument maker many essential parts are rightly hidden from view by protective devices, and the young student is deterred from meddling with them for fear of damaging valuable property.

\section{Simple Apparatus in Physics Research}

IN the same address Lord Rayleigh claims that beginners in research also should be "graduates in the school of string and sealing wax". Faraday, and Maxwell in such constructions in the Cavendish Laboratory as his model of the thermodynamic surface, are each quoted as examples. Sir Charles Parsons, the greatest mechanical engineer of his generation, was able to deal with formidable problems 